\title{
FORMAÇÃO DOCENTE: REFLEXÕES SOBRE O ESTÁGIO CURRICULAR
}

\section{Teacher training: reflections about the curricular stage}

\author{
Jeâni Kelle Landre Rosa ${ }^{1}$ • Célia Weigert ${ }^{2}$ • Ana Cristina \\ Gonçalves de Abreu Souza ${ }^{3}$
}

Resumo: O presente artigo apresenta reflexões e discussões sobre a importância e o papel do estágio curricular na formação prática de alunos do curso de licenciatura em Ciências Biológicas. A partir da análise do estágio curricular dos acadêmicos do $7^{\circ}$ e $9^{\circ}$ período, foram identificados os aspectos favoráveis e desfavoráveis e formuladas sugestões que visam melhorar a qualidade do mesmo. A pesquisa acerca da realidade e dos problemas do estágio supervisionado foi realizada por meio de análise documental (diário de campo e narrativas) e questionários. Com auxílio da literatura especializada, conseguimos aprofundar a compreensão dos mecanismos de articulação entre teoria e prática no cotidiano escolar, o que poderá contribuir para a construção de um currículo mais coerente com a realidade da sala de aula da Educação Básica.

Palavras-chave: Estágio. Formação de professores. Ensino Superior. Ensino de ciências. Ensino de biologia.

\begin{abstract}
This article presents some discussions and thoughts about the importance and role of curricular internship in the practical training in the Biological Sciences. With the analysis of the students from $7^{\text {th }}$ and $9^{\text {th }}$ semester's curricular internship, we identified the favorable and unfavorable points and suggestions for improving the quality of it. The survey of supervised internship's reality and problems was done through two qualitative methods: documental analysis (field journal and narratives) and questions. With the help of specialized literature, we can deepen the comprehension of the articulation mechanisms between theory and practical in the pupils' daily experience, which could contribute to building a more coherent curriculum related to the reality of classroom in elementary education.
\end{abstract}

Keywords: Curricular internship. Teacher training. Higher education. Science education. Biology teaching.

\footnotetext{
${ }^{1}$ Departamento de Ciências Exatas e Tecnológicas, Universidade Estadual de Santa Cruz (UESC). Campus Soane Nazaré de Andrade, Km 16. Rodovia Ilhéus-Itabuna. Ilhéus, BA, Brasil.

45.662-900. simonigehlen@yahoo.com.br

${ }^{2}$ Programa de Pós-Graduação em Educação nas Ciências, Universidade Regional do Noroeste do Estado do Rio Grande do Sul. Ijuí, RS, Brasil.

${ }^{3}$ Programa de Pós-Graduação em Educação Científica e Tecnológica, Universidade Federal de Santa Catarina. Florianópolis, SC, Brasil.
} 


\section{Introdução}

O que se pode perceber durante todo um curso de licenciatura em Ciências Biológicas, é a dificuldade sentida pelos alunos em lidar com a realidade da sala de aula e com a complexidade dos saberes que servirão de base ao ofício docente.

[...] o saber docente não é uma coisa que flutua no espaço: o saber dos professores é o saber deles e está relacionado com a pessoa e a identidade deles, com a sua experiência de vida e com sua história profissional, com as suas relações com os alunos em sala de aula e com os outros atores escolares na escola, etc. (TARDIF, 2002, p. 11)

Os saberes da formação docente constituem um conjunto de saberes provenientes da articulação entre teoria e prática. É a partir da prática que os licenciados poderão, diante do novo, revisar e agregar outros sentidos aos aprendidos na teoria, sendo esta ação chamada por Andrade (2006) de "reorquestração dos saberes".

A relação entre teoria e prática pode ser fundamentada em dois esquemas: a visão dicotômica, que está centrada na separação das duas, com ênfase na total autonomia de uma em relação à outra; e a visão de unidade, na qual ambas são componentes indissolúveis como práxis (CANDAU; LELIS, 1999). Concebe-se o ofício docente como algo que abarca aspectos teóricos e práticos e nos remete ao conceito de práxis - em que vamos a Freire (1983, p. 40) para fortalecer nossos princípios: “[...] a práxis, porém, é ação e reflexão dos homens sobre o mundo para transformá-lo". No entanto, ainda presenciamos, em muitos cursos de licenciatura, concepções que dicotomizam o conhecimento teórico e prático no cotidiano escolar.

Selles e Ferreira (2008) problematizam a formação docente no Brasil mostrando que a formação profissional se encontra ancorada na apropriação de conhecimentos e de práticas aprendidas em contextos acadêmicos não diretamente transferíveis para o contexto escolar, e, com isso, o mundo acadêmico tende a se distanciar do cotidiano escolar. Nos currículos dos cursos de licenciatura, a educação passa a ser considerada uma ciência aplicada, fundamentando-se na concepção epistemológica da racionalidade técnica.

Os currículos são normativos, com a sequência de conhecimentos dos princípios científicos relevantes, seguidos da aplicação destes princípios e de um practicum, cujo objetivo é aplicar na prática cotidiana os princípios da ciência estudada. Dentro da racionalidade técnica o desenvolvimento de competências profissionais deve colocar-se, portanto após o conhecimento científico básico e aplicado, pois não é possível aprender competências e capacidades de aplicação antes do conhecimento aplicável. (PÉREZ GOMES, 1992, p. 98)

A concepção de racionalidade técnica ganha destaque quando se considera a limitação adotada por instituições universitárias em ensinar os futuros profissionais a tomarem decisões que visem à aplicação técnica de conhecimentos científicos (SCHÖN, 1992). Entretanto, é de grande importância o entendimento de que a formação docente não se constrói 
apenas por acumulação de conhecimentos ou de técnicas, mas, também, por meio de uma reflexão crítica sobre as ações frente ao cotidiano escolar (PIMENTA, 2002), pois é durante a formação inicial que os futuros professores vivenciam situações práticas, como, por exemplo, a organização de situações de ensino e suas aplicações em sala de aula (LONGHINI, 2001).

A formação docente trata de um conhecimento pessoal e não sistemático. Por esse motivo, a prática se torna essencial, pois somente ela conduz necessariamente à criação de um conhecimento específico e ligado à ação (GARCIA, 1992). Portanto, a função da prática, segundo Freire (1983), é a de agir sobre o homem para transformá-lo. Nesta perspectiva, o estágio nos cursos de formação de professores é de grande relevância, pois, sem dúvida, é o espaço de conciliação entre as disciplinas fundamentalmente específicas do curso e as pedagógicas.

A imersão na realidade da sala de aula, mediante o estágio, fará com que os futuros professores estabeleçam, em torno da prática, um exercício de reflexão, proporcionando, ao licenciando, a possibilidade de um olhar mais centrado e profundo sobre a complexidade da realidade escolar e educacional (BEHRENS, 1991). No entanto, o saber docente também deve ser nutrido pelas teorias da educação, não sendo formado apenas da prática. Pimenta e Ghedin (2002) destacam a importância fundamental que a teoria tem na formação dos docentes, pois adota os sujeitos de variados pontos de vista para uma ação contextualizada, oferecendo perspectivas de análise para que os professores compreendam os diversos contextos vivenciados por eles.

Nessa perspectiva, o estágio deve ser identificado como um elemento facilitador da articulação entre teoria e prática, e como uma aproximação da realidade profissional - e não como a prática em si, uma vez que os alunos permanecem ali por um período de tempo limitado, sem conquistarem um espaço considerável de autonomia. Logo, não realizam a prática, mas se aproximam dela para efetuar algum tipo de atividade considerada pertinente ao seu processo de formação (SANTOS, 2004).

Compreender o Estágio Curricular como um tempo destinado a um processo de ensino e de aprendizagem - em uma oportunidade para refletir, sistematizar e testar conhecimentos durante o curso de graduação (não sendo, simplesmente, uma experiência prática) - é reconhecer que, apesar da formação oferecida em sala de aula ser fundamental, ela sozinha não é suficiente para preparar os alunos para o pleno exercício de sua profissão.

De acordo com o Conselho Nacional de Educação, o Estágio Curricular é definido como um:

[...] tempo de aprendizagem que, através de um período de permanência, alguém se demora em algum lugar ou ofício para aprender a prática do mesmo e depois poder exercer uma profissão ou ofício. Assim o estágio supõe uma relação pedagógica entre alguém que já é um profissional reconhecido em um ambiente institucional de trabalho e um aluno estagiário. (BRASIL, 2001, p. 10)

[...] se constitui umas das condições para a obtenção da licença para o exercício profissional na medida em que é considerado o momento de efetivar, sob a supervisão de um professor experiente, um processo de ensino-aprendizagem em que se tornará concreto e autônomo quando da profissionalização deste estagiário. (BRASIL, 2001, p. 10) 
Momento de formação profissional, seja pelo exercício direto in loco, seja pela presença participativa em ambientes próprios daquela área profissional, sob a responsabilidade de um profissional habilitado. (BRASIL, 2001, p. 10)

O aluno de graduação, durante o estágio, vivencia experiências, conhece melhor sua área de atuação e tem a oportunidade de aplicar os conhecimentos teóricos adquiridos. $\mathrm{O}$ estágio surge, então, como um processo fundamental na formação do aluno estagiário, pois é a forma de fazer a transição de aluno para professor.

A complexidade do processo de ensinar e aprender é reconhecidamente profunda, e requer ações dentro do contexto do estágio proposto pela dinâmica curricular dos cursos de licenciatura.

O estágio curricular é, portanto, indispensável na construção da identidade profissional, uma vez que a profissão de professor não pode ser considerada uma ciência aplicada, sendo que o envolvimento humano não pode ser sistematizado, devendo haver um contato mais intenso para gerar o conhecimento.

O presente trabalho, inserido na linha de pesquisa Formação de Professores, no contexto da formação inicial de professores, tem como objeto de estudo analisar a forma com que o estágio supervisionado contribui para o processo de desenvolvimento da formação profissional de futuro docente, bem como fazer uma reflexão sobre a relação do licenciando com a prática de ensino/Estágio supervisionado.

\section{O curso de licenciatura em Ciências Biológicas da Universidade Federal de Alfenas (UNIFAL-MG)}

O curso de Ciências Biológicas da Universidade Federal de Alfenas foi criado em 3/ 8/1999, sob a Resolução No 003/99 e Portaria do MEC No 1202, seguindo a fórmula "3+1": de acordo com Pereira (1999), o número " 3 " representava os três anos destinados ao desenvolvimento das disciplinas da área específica de Biologia, enquanto o número "1" representava o período de um ano destinado ao desenvolvimento das disciplinas de natureza pedagógica.

Em 12/04/2002, o curso foi desmembrado em Bacharelado e Licenciatura. A Modalidade Licenciatura foi autorizada sob a Resolução No 005/2002 do Conselho Superior, sendo iniciado em 02/09/2002.

A partir do meio do ano de 2007, a grade curricular do curso passou por mudanças significativas. A carga horária total do curso de licenciatura em Ciências Biológicas aumentou de 2.805 horas para 3.450 horas; as disciplinas pedagógicas, que antes compreendiam 25,1\%, agora compreendem cerca de $54 \%$ do curso. Esse aumento deve-se à uniformização das disciplinas pedagógicas do Curso de Ciências Biológicas Licenciatura com as outras licenciaturas da Universidade Federal de Alfenas. As modalidades Licenciatura e Bacharelado passaram a ter as mesmas disciplinas básicas específicas, com carga horária equivalente, e, para isso, houve um aumento de 1.065 horas nas disciplinas específicas da modalidade Licenciatura. Também foram incorporadas à grade curricular nova da modalidade Licenciatura 405 horas para a prática das disciplinas pedagógicas, que correspondem ao tempo em que o aluno desenvolverá alguma atividade fora do contexto universitário. 
Formação docente: reflexões sobre o estágio ...

A dinâmica antiga possuía quatrocentas horas destinadas ao estágio supervisionado, no qual o aluno começava a ter contato com o cotidiano escolar desde o $3^{\circ}$ período do curso. $\mathrm{Na}$ dinâmica atual, o estágio passa a ter 405 horas, sendo realizado a partir do $6^{\circ}$ período.

O Estágio caracteriza-se pelo desenvolvimento de atividades relacionadas à docência em escolas de Ensino Fundamental e Médio, bem como em outros ambientes educativos, programadas em consonância com as Práticas de Ensino, com as quais deve ocorrer concomitantemente, uma vez que tratam-se de áreas intimamente articuladas, conforme o Parecer CNE/CP 28/2001 (BRASIL, 2001).

O licenciado em Ciências Biológicas é responsável pelo aperfeiçoamento do processo educativo, sendo, portanto, um profissional capacitado como educador. No entanto, o perfil dos alunos egressos é totalmente diferente: cerca de $70 \%$ desses alunos não vão para sala de aula quando se formam, preferindo a área de pesquisa e continuando seus estudos em nível de pós-graduação em áreas não correlatas à educação.

\section{Campo empírico}

A pesquisa foi realizada com 46 acadêmicos do curso de licenciatura em Ciências Biológicas da Universidade Federal de Alfenas, dos quais 24 estão matriculados na disciplina Laboratório de Ensino de Biologia I, e os 22 restantes estão matriculados em Laboratório de Ensino de Biologia II.

Como o principal objetivo deste trabalho é adentrar a realidade dos estagiários, compreender e explorar suas opiniões, percepções, anseios, dúvidas, expectativas e concepções a respeito da profissão docente e do cotidiano escolar, optou-se pelo estudo de cunho qualitativo, por ser de caráter observativo, descritivo e de compreensão da realidade.

A pesquisa qualitativa responde a questões muito particulares. Ela se preocupa com um nível de realidade que não pode ser quantificado, ressalta a subjetividade, trabalha com um universo de significados, motivos, aspirações, valores e atitudes (MINAYO, 1994). Vale ressaltar que a investigação qualitativa busca pela análise dos dados em toda a sua riqueza, na forma em que foram registrados e transcritos, tratando-se de maneira descritiva (BOGDAN; BIKLEN, 1994).

Para esse estudo, foram utilizados dois tipos de métodos qualitativos. Em um primeiro momento, fez-se o uso da análise de conteúdo das narrativas e diárias de campo dos acadêmicos matriculados nas disciplinas de Laboratório de Ensino de Ciências I e II. A análise documental pode se constituir numa técnica valiosa de abordagem de dados qualitativos, seja complementando as informações obtidas por outras técnicas, seja desvelando aspectos novos de um tema ou problema (LUDKE; ANDRÉ, 1986).

As narrativas podem ser caracterizadas através de três dimensões: da investigação sobre as experiências vividas; da formação, que evidencia os fatos investigados em confronto com o desenvolvimento profissional do professor; e, por último, a dimensão da reflexão pedagógica, que permite compreender a atuação profissional (GALVÃO, 2005).

De acordo com Zabalza (1994), Porlan e Martin (1997), o diário de campo nos remete a narrações com dimensões objetivas e subjetivas sobre os processos mais significativos de suas ações. Sua realização possibilita uma perspectiva da evolução e desenvolvimento profis- 
sional desses futuros docentes num determinado período de tempo. Os registros dos pensamentos e sentimentos que experimentam durante o processo de ensino das atividades envolvidas no estágio possibilitam, aos futuros professores, construírem uma visão mais objetiva e completa da realidade que constitui sua ação, além de estabelecerem conexões significativas entre o conhecimento teórico e prático.

Em um segundo momento, os dados foram coletados através de uma entrevista/ questionário. De acordo com Bauer e Gaskell (2002), a entrevista qualitativa fornece os dados básicos para o desenvolvimento e a compreensão em relação aos comportamentos das pessoas em contextos sociais específicos.

[...] técnica de investigação composta por um número mais ou menos elevado de questões apresentadas por escrito às pessoas, tendo por objetivo o conhecimento de opiniões, crenças, sentimentos, interesses, expectativas, situações vivenciadas etc. (GIL, 1995, p. 124)

O questionário aplicado aos acadêmicos foi composto por 28 afirmativas, nas quais eles respondiam sim ou não; e seis questões abertas.

A narrativa, o diário de campo, a entrevista e o questionário mostraram ser instrumentos de investigação extremamente relevantes, pois através de todo o processo de leitura, análise dos resultados e das experiências vividas ao longo do estágio de observação e regência desses acadêmicos, pôde-se resgatar e compreender as vivências, as expectativas, as emoções e as percepções destes frente à realidade de uma sala de aula, além de se conseguir estabelecer relações entre o conteúdo das narrativas e dos diários.

Os resultados dos questionários e as reflexões dos diários de campo e das narrativas foram, posteriormente, agrupados de acordo com sua significação em: (a) perfil dos graduandos e identidade profissional; (b) opinião discente sobre organização/estrutura do Curso de Licenciatura em Ciências Biológicas; (c) opinião discente sobre o estágio supervisionado; (d) motivações e dificuldades vivenciadas pelos acadêmicos durante o estágio supervisionado.

A intenção é a de construirmos uma discussão crítico-reflexiva sobre o tema abordado, além de apresentarmos sugestões dos acadêmicos para a melhoria do estágio.

\section{Apresentação e discussão dos resultados}

\section{(a) Perfil dos graduandos e identidade profissional}

A faixa etária dos participantes da pesquisa (entrevistados) é diversificada, mas obteve-se uma média de 23,9 anos. Quanto ao gênero, predomina o sexo feminino, com 65,5\% dos entrevistados. No geral, $74,1 \%$ dos alunos que participaram da pesquisa realizam ou realizaram seus estágios em escola Estadual do Município de Alfenas, MG. O perfil socioeconômico dos alunos é variado: 65\% vieram de escolas particulares e mais de $90 \%$ não possuíam ou possuem vínculo empregatício durante o curso.

Quanto à questão da escolha do curso, $73 \%$ não tinham a licenciatura como primeira opção e não pretendem dar aulas depois de se formar; 75\% realizam pesquisas em áreas não correlatas à educação. Diversos são os motivos apontados pelos alunos para a escolha do 
Formação docente: reflexões sobre o estágio ...

Curso de licenciatura em Ciências Biológicas, entretanto a maior parte afirma tê-lo escolhido por ser oferecido no meio do ano. Percebe-se então, com estes dados, que os alunos não se veem como futuros professores, mesmo estando estudando para isso.

\section{(b) Opinião discente sobre a organização/estrutura do curso de Licenciatura em Ciências Biológicas}

Os dados mostram que 57,1\% dos entrevistados sentem-se incomodados com o atual currículo da licenciatura. A maioria acredita que o currículo deveria ser revisto e reformulado. No caso, a principal mudança apontada por $64,2 \%$ dos acadêmicos refere-se à transferência do estágio para o último período do curso - a alegação em defesa dessa mudança é de que os alunos teriam mais tempo para se dedicarem às atividades propostas.

A maioria dos graduandos (65\%) acredita que o Curso de Licenciatura em Ciências Biológicas da UNIFAL-MG não forma professores bem preparados para ministrar aulas no Ensino Fundamental e Médio. A esse respeito, os entrevistados falam, na pesquisa, que o curso tem como preocupação primordial a formação de biólogos, sendo a formação docente deixada em segundo plano, como ênfase do Curso de Ciências Biológicas. Esse quadro nos remete ao antigo sistema de " $3+1$ ", já discutido anteriormente, porém camuflado de "Modalidade".

O estudo também mostrou a importância que os acadêmicos dão à formação do professor para a realização de uma boa prática pedagógica, não sendo esta determinada pelo dom ou pelo domínio do conteúdo, e sim pela capacidade de o professor transformar um conteúdo teórico em algo que os alunos compreendam.

Para Mortimer (1998), um bom professor deve reconstruir o saber científico para ser utilizado no contexto escolar. Tal hipótese é confirmada pelos dados da pesquisa: 64,2\% afirmam não se sentir seguros para darem aula, e avaliam que o curso não os dá subsídios para essa reconstrução do saber científico. Por outro lado, de forma unânime, os entrevistados consideraram esse poder de reconstrução do saber científico uma característica relevante para o professor.

Cerca de $71 \%$ dos pesquisados acredita que o curso oferece disciplinas que ajudam a relacionar o conteúdo de biologia com o conteúdo pedagógico. No entanto, a dicotomia entre disciplinas específicas e pedagógicas também se revela para os alunos entrevistados, já que $71,4 \%$ aponta um distanciamento entre o conteúdo específico e a prática pedagógica - e a maioria afirmou haver um predomínio das disciplinas específicas na dinâmica curricular do curso. Quando questionados sobre a importância de ambas as disciplinas, a maioria dos estudantes acredita que tanto as disciplinas específicas quanto as pedagógicas deram subsídios para sua formação docente.

De acordo com Candau e Lelis (1999), essa abordagem dissociativa tende a enfatizar a formação teórica sem se preocupar em modificar ou fornecer instrumentos para a intervenção na prática educacional.

\section{(c) Opinião discente sobre o estágio supervisionado}

Soares, Lima e Quadro (2007) falam que a construção de qualquer carreira depende de uma base sólida. No caso da docência, a construção de tal base se inicia durante o curso de licenciatura e tem como uma de suas principais etapas o estágio curricular supervisionado.

Os dados revelam que os acadêmicos estão conscientes da importância do estágio para a sua formação docente: cerca de $93 \%$ não veem o estágio apenas como uma etapa 
obrigatória do curso; $52,4 \%$ não concordam que o estágio é completamente ilusório às reais situações encontradas na escola; e 71,4\% acreditam que o estágio curricular é de extrema relevância, pois é entendido como o eixo central na formação de professores.

Aproximadamente $72 \%$ dos entrevistados acreditam que o estágio supervisionado é responsável por diminuir o choque entre o mundo acadêmico e o cotidiano escolar, aumentando as possibilidades do estudante de ser inserido na realidade da escola. No entanto, não há um consenso entre os estudantes de que esta é a única disciplina que permite relacionar as teorias pedagógicas com a prática escolar - apenas 42,8\% concordam com esta afirmativa.

De acordo com Tardif e Raymond (2000), o confronto com a realidade forçará os futuros professores a questionarem a visão idealista que possuem sobre a profissão docente. Distanciados do conhecimento acadêmico e mergulhados no exercício da profissão, passam a reajustar suas expectativas e percepções anteriores. O estágio supervisionado consiste em teoria e prática, buscando, constantemente, a realidade para uma elaboração de trabalho na formação do educador (GUERRA, 1995 apud SOUZA; BONELA; PAULA, 2007). Nessa perspectiva, o estágio supervisionado deve levar o estagiário a várias práticas e a vários modos de ser professor.

$\mathrm{Na}$ opinião de Carvalho (1985), os estágios seguem um ciclo tradicional, que consiste em observação, regência e participação, todos acompanhados e supervisionados pelo docente responsável pela prática de ensino/Estágio supervisionado.

Os estágios de observação têm por objetivo levar o aluno à análise e à reflexão da prática docente, e fornecer subsídios para o desenvolvimento dos estágios de regência. No entanto, Carvalho (1985) ressalta o que acontece na maioria dos estágios de observação: a ênfase maior está em elencar defeitos sem a preocupação de corrigi-los, fazendo com que os regentes observados sintam-se julgados. Esse quadro é confirmado por $60 \%$ dos alunos entrevistados, para os quais o estágio de docência de observação não traz nenhuma contribuição, já que se resume a observar o cotidiano escolar e, consequentemente, o professor regente, enumerando os erros e os acertos, sem nenhum intuito específico. Abaixo, as principais justificativas dos acadêmicos em relação a esta questão:

"O Estágio de observação não contribuiu em nada para minha formação, pois não vejo objetivo nenhum em somente observar. Observação eu fiz minha vida inteira na escola enquanto aluno.” (A30)

"Estágio de observação, sinceramente não contribui em nada, apenas você vê e pensa em não repetir, mas acho que o processo educacional necessita de uma reciclagem e não somente ficar vendo atitudes ruins de certos professores e evitá-las, tem que ter inovação e para isso precisa haver um contato ATIVO com os alunos, sem isso não dá pra saber de onde partir para que o processo ensino/aprendizagem seja melhorado." (A20)

"Nenhuma! São todos a mesma coisa!! E quando chegamos pra dar uma aula (que é quase impossível nas escolas), nós nos deparamos com as mesmas dificuldades que nós observamos quando estávamos 
Formação docente: reflexões sobre o estágio ...

somente acompanhando as aulas. E ainda por cima não dá pra ter base de como é ser professor somente vendo as aulas." (A17)

"Nenhuma, pois na maioria das vezes nem prestamos atenção no que o professor está falando." (A13)

Já o estágio de regência refere-se à inserção do estudante de forma direta no cotidiano escolar. São vivenciadas experiências docentes de forma integrada e participativa, nas quais o estudante assume responsabilidade pela turma, desenvolvendo atividades de docência adquiridas durante o curso. Quando questionados sobre a contribuição do estágio de regência, 75\% dos acadêmicos afirmaram ser de extrema importância para sua formação, pois é uma forma de vivenciar a docência.

"O estágio de regência contribuiu na experiência do preparo das aulas, convivência com os alunos, lidar com imprevistos." (A10)

"É de extrema importância, pois é a única e real possibilidade de vivenciar o ato da docência." (A9)

"Na regência são muitas as experiências que se adquire, a interação é ativa tanto por parte dos alunos como da minha parte. Tive ótimas experiências de regência, mesmo sendo apenas 2 dias foi mais vantajoso e com muitas experiências, acredito que valeu mais que o restante de horas que fiquei vendo as mesmas aulas. Inclusive os próprios alunos disseram que nesse dia a aula tinha sido interessante, então acredito que valeu a pena. Pra mim foi muito mais construtivo dar esses 2 dias de regência, do que observar 90 horas de aula, tenho certeza que cresci muito mais na minha formação, fui mais questionada por mim mesma para rever a maneira de explicar os assuntos de um modo mais acessível, além de poder levar pra sala de aula alguns temas que estão em alta no mundo, mas que na escola se trata superficialmente. Em resumo, foi muito gratificante pra mim dar essa regência na escola, cresci muito na minha formação como professora de biologia." (A20)

\section{(d) Motivações e dificuldades vivenciadas pelos acadêmicos do Curso} de Licenciatura em Ciências Biológicas durante o Estágio Supervisionado

Dos entrevistados, $82 \%$ sentem-se desmotivados perante o estágio curricular. Dentre os principais fatores que cooperam para essa desmotivação estão: dificuldade de conseguir estágios; desvio de papéis dos estagiários; falta de apoio/auxílio dos profissionais envolvidos na área; e choque com a realidade.

O principal problema destacado pelos entrevistados é quanto ao número reduzido de escolas e a dificuldade para arranjarem estágios. De acordo com $93 \%$ dos entrevistados, há um distanciamento entre o mundo acadêmico e o cotidiano escolar, sendo esse um dos principais motivos para a dificuldade na inserção do estagiário na escola. 
"Um dos principais problemas é quanto à aceitação. São poucas as escolas que nos recebem logo da primeira vez que procuramos." (A7)

"No início, achar alguma escola que aceite receber estagiários seguindo as propostas do estágio exigidas pelos professores das disciplinas que tem estágio obrigatório." (A22)

"Para conseguir uma escola que aceite um estagiário." (A14)

"Sempre há restrições para realização de estágios. Principalmente no âmbito da disposição de vagas, na recepção das escolas e dos professores que sempre se incomodam com a presença dos estagiários. Enfim, não há como ficar motivado com tal situação.” (A35)

O fato da dificuldade em conseguir estágios nos remete a outro problema bastante relevante, que é a total falta de apoio da escola para com o estagiário e, consequentemente, o desvio de papéis do mesmo. Muitas vezes, o estagiário submete-se a atividades que não correspondem ao que é proposto nos currículos de formação de professores, para conseguir inserirse no cotidiano escolar e cumprir a carga horária referente ao estágio supervisionado.

"O problema maior é conseguir o próprio estágio. Às vezes tem que se sujeitar a tudo, quase que implorar para poder realizar o estágio. Parece que a escola nos faz um imenso favor permitindo nossa entrada na sala de aula." (A20)

"Assim como no semestre passado, minha maior atividade realizada foi o trabalho com as crianças em aulas de reforço. Ensino muito mais português e matemática do que ciências. A escola não liga muito com o fato de eu ser graduanda de biologia." (A37)

"Ao invés de ficar sentado com as crianças na porta da sala "tomando" a leitura delas..." (A42)

Outra questão levantada durante as entrevistas foi quanto à falta de apoio/auxílio dos profissionais envolvidos na área. 59\% dos acadêmicos afirmam que não tiveram apoio do professor responsável pela disciplina Laboratório de Ensino de Biologia/Ciências e do regente da disciplina de ciências/biologia.

"Pelo fato de que quando chegamos na escola os professores não nos incentivam e muito menos nos dão oportunidade de podermos ver uma forma melhor para abordar e passar o conteúdo para os alunos." (A21) 
Formação docente: reflexões sobre o estágio ...

"Problemas de ficar sem saber o que fazer, o que oferecer e o que observar - novamente pela falta de um roteiro que destine tantas horas para observação, tantas para regência, etc." (A17)

"Um dos principais problemas é a falta de assistência do professor responsável pela disciplina.” (A23)

"Não há fundamentação por parte da professora que deixa por conta dos alunos planejarem um estágio sem roteiro.” (A33)

Dos entrevistados, 64,2\% afirmaram ter sentido dificuldades no estágio de regência devido ao choque com a realidade escolar (dificuldade de expor o conteúdo, falta de interesse dos alunos, ter de enfrentar o inesperado, dar aula sem ter tempo para preparar). Essa questão nos remete a Pimenta (2006), que destaca que, muitas vezes, os estagiários ficam confusos durante a regência porque percebem que os conteúdos aprendidos durante todo o curso não condizem com a realidade da sala de aula do Ensino Fundamental e Médio.

"O maior dos problemas com estágio é conseguir transmitir algo realmente aos alunos, e quando isso não ocorre, principalmente por falta de interesse deles, nós acabamos desistindo de continuar tentando."

“A desvalorização do professor perante os alunos." (A12)

"Outro fato interessante deste estágio foi que já no segundo dia do estágio uma professora faltou então tive que ficar na sala de aula, obviamente fiquei apavorada, uma sala de 30 alunos do $6^{\circ}$ ano, para alguém que estava somente no segundo dia de estágio, para mim estava indo para forca." (A37)

"A professora que acompanhávamos faltou uma semana inteira, sem avisar com antecedência, e nós tivemos que nos virar e dar as aulas." (A25)

\section{(e) Quanto às sugestões dos acadêmicos} para melhoria do Estágio Supervisionado

Segundo Xavier e Santos (1998), as ideias de mudança na qualidade educativa, e, consequentemente, necessidade de melhoria da mesma, surgem diante de situações problemáticas. Nesse contexto de mudanças, os acadêmicos apontam algumas "sugestões para melhoria do estágio curricular".

Dentre as sugestões dos entrevistados, duas se destacaram. A primeira, já discutida anteriormente, seria transferir o estágio para o último período, separado das outras disciplinas. A segunda sugestão mais citada foi quanto à substituição do estágio de observação e regência, por elaboração e aplicação de projetos nas escolas. 
Rosa, J. K. L.; Weigert, C.; Souza, A. C. G. A.

\section{Considerações finais}

Esta pesquisa possibilitou um maior entendimento da importância do estágio supervisionado no curso de Licenciatura em Ciências Biológicas da UNIFAL-MG. Através dos dados obtidos pelos questionários, diários de campo, narrativas, e com ajuda da literatura especializada, percebemos mais claramente a ocorrência de choque do acadêmico com a realidade escolar. Esse fato denuncia duas situações: que o currículo ainda é precário quanto à preparação do futuro professor; e que ainda existem acadêmicos que procuram o curso de licenciatura sem, na verdade, desejarem ser professores.

Analisando os resultados, podemos constatar que o currículo do Curso de Licenciatura em Ciências Biológicas da UNIFAL-MG ainda baseia-se na regra do " $3+1$ ", dando preferência à dicotomia entre teoria e prática, transformando o professor em um especialista da profissão biólogo.

Outro aspecto que é importante ressaltar é quanto à qualidade da orientação/supervisão dos professores responsáveis pela disciplina Laboratório de Ensino de Biologia/Ciências. Salientamos que esta ação é determinante no desempenho dos estagiários em sua docência e precisa ser sempre repensada. Outra questão que deve ser trabalhada é com relação à conscientização das escolas e professores regentes da importância do Estágio para os futuros professores, além de se fazer um planejamento prévio entre as escolas e a Universidade, visando à inserção dos alunos estagiários dentro do contexto escolar.

Mesmo com toda a problemática que envolve o Estágio Curricular, constatamos que há uma valorização desta disciplina e a consciência de que ela é de extrema importância, para a formação profissional, pelos acadêmicos. No entanto, é necessário realizar uma permanente reflexão sobre o seu desenvolvimento, para a busca da melhoria da qualidade do ensino.

\section{Referências}

ANDRADE, E. P. Um trem rumo às estrelas: a oficina de formação docente para o ensino de história (o curso de história da FAFIC). 2006. 282 f. Tese (Doutorado em Educação) - Faculdade de Educação, Universidade Federal Fluminense, Niterói, 2006. Disponível em: <http://www.uff.br/pos_educacao/joomla/images/stories/Teses/ andradet2006.pdf $>$. Acesso em: 05 nov. 2010.

BAUER, M.; GASKELL, G. (Org.). Pesquisa qualitativa com texto, imagem e som: um manual prático. Petrópolis: Vozes, 2002.

BEHRENS, M. A. O estágio supervisionado de prática de ensino: uma proposta coletiva de reconstrução. 1991. 151 f. Dissertação (Mestrado em Educação) - Pontifícia Universidade Católica de São Paulo, São Paulo, 1991.

BOGDAN, R. C.; BIKLEN, S. K. Investigação qualitativa em educação: uma introdução à teoria e aos métodos. Porto: Porto Editora, 1994. 
Formação docente: reflexões sobre o estágio ...

BRASIL. Ministério da Educação. Parecer CNE/CP 28/2001. Dá nova redação ao Parecer CNE/CP 21/2001, que estabelece a duração e a carga horária dos cursos de Formação de Professores da Educação Básica, em nível superior, curso de licenciatura, de graduação plena. Brasilia, 2001.

CANDAU, V. M.; LELIS, I. A. A relação teoria-prática na formação do educador. In: CANDAU, V. M. (Org.). Rumo a uma nova didática. 10. ed. Petrópolis: Vozes, 1999. p. 56-72.

CARVALHO, I. M. O processo didático. Rio de Janeiro: FGV, 1985.

FREIRE, P. Pedagogia do oprimido. 13. ed. Rio de Janeiro: Paz e Terra, 1983.

GALVÃO, C. Narrativas em educação. Ciência \& Educação, Bauru, v. 11, n. 2, p. 327-345, 2005. Disponível em: <http://www.scielo.br/pdf/ciedu/v11n2/12.pdf>. Acesso em: 15 nov. 2010.

GARCÍA, C. M. A formação de professores: novas perspectivas baseadas na investigação sobre o pensamento do professor. In: NÓVOA, A. (Org.). Os professores e a sua formação. Lisboa: Dom Quixote, 1992. p. 51-76.

GIL, A. C. Métodos e técnicas de pesquisa social. 4. ed. São Paulo: Atlas, 1995.

LONGHINI, M. D. Aprender para ensinar: a reflexão na formação inicial de professores de física. 2001. 353p. Dissertação (Mestrado em Educação para a Ciência) - Faculdade de Ciências, Universidade Estadual Paulista, Bauru, 2001.

LUDKE, M.; ANDRE, M. E. D. Pesquisa em educação: abordagens qualitativas. São Paulo: EPU, 1986.

MINAYO, M.C. O desafio do conhecimento. São Paulo: Hucitec; Abrasco, 1994.

MORTIMER, E. F. Sobre chamas e cristais: a linguagem científica, a linguagem cotidiana e o ensino de ciências. In: CHASSOT, A.; OLIVEIRA, R. J. (Org.). Ciência, ética e cultura na educação. São Leopoldo, Unisinos, 1998. p. 99-118.

PEREIRA, J. E. D. As licenciaturas e as novas políticas educacionais para a formação docente. Educação \& Sociedade, Campinas, v. 20, n. 68, p. 109-125, dez. 1999.

PÉREZ GOMES, A. Formação dos professores da licenciatura: os professores e sua formação. Porto: Porto Editora, 1992.

PIMENTA, S. G. (Org.). Saberes pedagógicos e atividade docente. 3. ed. São Paulo: Cortez, 2002.

PIMENTA, S. G. O estágio na formação de professores: unidade teoria e prática? 7. ed. São Paulo: Cortez, 2006.

PIMENTA, S. G.; GHEDIN, E. (Org.). Professor reflexivo no Brasil: gênese e crítica de um conceito. 3. ed. São Paulo: Cortez, 2002.

PORLAN, R.; MARTIN, J. El diário del profesor: un recurso para la investigacion en el aula. Sevilla: Díada, 1997. 
Rosa, J. K. L.; Weigert, C.; Souza, A. C. G. A.

SANTOS, H. M. dos. O estágio curricular na formação de professores: diversos olhares. 2004. 142 f. Dissertação (Mestrado em Educação) - Pontifícia Universidade Católica de São Paulo, São Paulo, 2004.

SCHÖN, D. Formar professores como profissionais reflexivos. In: NÓVOA, A. Os professores: sua formação. Lisboa: D. Quixote, 1992. p. 81-91.

SELLES, S. E.; FERREIRA, M. S. O professor de ciências e o movimento renovador dos anos de 1950/70: um estudo sócio-histórico. In: CONGRESSO LUSO-BRASILEIRO DE HISTÓRIA DA EDUCAÇÃO, 7., 2008, Porto. Actas... Porto: Universidade do Porto, 2008.

SOARES, R. T. C.; LIMA, M. E. C. C.; QUADRO, A. L. Importância e dificuldades do estágio curricular obrigatório. Belo Horizonte: Universidade Federal de Minas Gerais, 2007.

SOUZA, J. C. A.; BONELA, L. A.; PAULA, A. H. A importância do estágio supervisionado na formação do profissional de educação física: uma visão docente e discente. Movimentum: Revista Digital de Educação Física, Ipatinga, v. 2, n. 2, 2007. Disponível em: < http://www.unilestemg.br/movimentum/index_arquivos/ movimentum_V2_N2_souza_janua_luciane_bonela_2_2006.pdf $>$. Acesso em: 05 nov. 2010 .

TARDIF, M. Saberes docentes e formação profissional. Petrópolis: Vozes, 2002.

TARDIF, M.; RAYMOND, D. Saberes, tempo e aprendizagem do trabalho no magistério.

Educação \& Sociedade, Campinas, v. 21, n. 73, p. 209-244, dez. 2000.

UNIVERSIDADE FEDERAL DE ALFENAS. Projeto pedagógico: curso de ciências biológicas. Alfenas: Unifal-MG, 2007. Disponível em: <http://www.unifal-mg.edu.br/ graduacao/sites/default/files/

Projeto\%20Pedagogico \%20CB\%202007\%20resolu\%C3\%A7\%C3\%A3o\%2042\%202007_0.pdf>. Acesso em: 15 nov. 2010.

XAVIER, B. M.; SANTOS, L. H. R. dos. Aulas de educação física: o que mudar na opinião dos alunos. In: SIMPÓSIO NACIONAL DE GINÁSTICA E DESPORTO, 28., 1998, Pelotas. Livro de resumos... Pelotas: UFPEL, 1998. p. 31.

ZABALZA, M. Diários de aula: contributo para o estudo dos dilemas prático dos professores. Porto: Porto Editora, 1994.

Artigo recebido em 12/05/2011. Aceito em 23/11/2011. 